\title{
Laboratory method design for investigating the phytoremediation of polluted water
}

\author{
DM Jacklin', IC Brink² and J de Waal ${ }^{*}$ \\ 'Department of Geography and Environmental Studies, Stellenbosch University, Private Bag X1, Matieland 7602, South Africa \\ ${ }^{2}$ Department of Water and Environmental Engineering, Stellenbosch University, Private Bag X1, Matieland 7602, South Africa
}

\begin{abstract}
The performance of plants to remove, remediate or immobilise environmental contaminants in a growth matrix through natural biological, chemical or physical activities was studied in a laboratory phytoremediation system. This study aimed to develop a novel phytoremediation system capable of investigating the remediation of agricultural pollutants by individual and multiple plant species. The designed system analysed community phytoremediation by uniquely implementing multiple plant species within the same growth silo, with indigenous and alien assemblages compared to establish community performance, highlighting the importance of biodiversity in plant assemblages. The constructed system successfully analysed the phytoremediatory capabilities of plant species within the critically endangered Renosterveld vegetation type, with unvegetated soil controls included to illustrate the pollutant removal efficiency of plants only. Growth silos were constructed from PVC piping and irrigated with drippers from a submersible pump. Eighteen different plant species were included in the experiment, i.e., 14 indigenous species, 3 invasive alien plant (IAP) species, and Palmiet. Five agricultural pollutant parameters were analysed, i.e., for fertilizers $\mathrm{NH}_{3}-\mathrm{N}, \mathrm{NO}_{3}{ }^{-} \mathrm{N}$ and $\mathrm{PO}_{4}{ }^{3-}-\mathrm{P}$ and for herbicide contamination using two glyphosate concentrations. The growth silos and unvegetated soil control were irrigated using a pollutant-municipal water solution at 3-day intervals. The multiple plants per silo design approach seeks to contribute to the limited literature pertaining heterogeneity importance, by comparing the pollutant removal performance of plant assemblages. Community comparison further investigated the biofilter implementation potential of indigenous South African plants as an alternative to their more invasive alien counterparts, adding to the knowledge base of plant-based phytoremediation by indigenous South African plant species. The laboratory phytoremediation system successfully measured the agricultural pollutant removal performance of individual plants and vegetative communities, with soil remediation influence acknowledged. The proposed system is a simple and inexpensive method for obtaining the plant-based biofiltration efficiency of individual and multiple plant species.
\end{abstract}

Keywords: experimental design, phytoremediation, water quality, bioremediation

\section{INTRODUCTION}

Globally, terrestrial surface and groundwaters are affected by pollution from a range of industrial and agricultural activities (Schoumans et al., 2014). In particular, fertilizers and pesticides, derived from various agricultural practices, lead to the degradation of both surface and groundwater (Barcelo, 1997; Donoso et al., 1999; Lam et al., 2010). Diffuse water pollution from agricultural applications carry an immense cost to society, including environmental and ecosystem damage, loss of aquaculture and fisheries income and increased treatment costs for drinking water (Norse et al., 2001; Norse, 2005; Smith and Siciliano, 2015). Nitrogen (N) and phosphorus $(\mathrm{P})$ fertilizers, and glyphosate-based $\left(\mathrm{C}_{3} \mathrm{H}_{8} \mathrm{NO}_{5} \mathrm{P}\right)$ herbicides, can cause nutrient loading and widespread water quality degradation to both surface and groundwater (Schachtschneider et al., 2010; Hashemi et al., 2016). However, vegetation buffers between agricultural fields and watercourses can potentially slow the migration of chemicals, thus limiting agricultural pollutants into adjacent waterways (Campbell, 1999; Beltrano et al., 2013). Due to the hazardous effects of agricultural pollutants on the environment, specifically non-point source aquatic ecosystem pollution, techniques to reduce nutrient and herbicide discharge must be developed (Tesfamariam et al., 2009; Schoumans et al., 2014).

*Corresponding author, email: janniedw@sun.ac.za

Received 1 October 2018; accepted in revised form 26 September 2019
In developing countries phytoremediation has become a technology of choice for remediation projects, due to costeffectiveness and implementation ease (Terry and Banuelos, 1999). The technique additionally takes into account the probable end-use of the site once it has been remediated (PilonSmits, 2005). Conventional approaches to remediation often produce infertile soil by destroying the microenvironment (Kennen and Kirkwood, 2015). Additionally, knowledge regarding the phytoremediatory capabilities of individual plant species is limited. Since plants and soils respond differently when exposed to polluted water, it is essential to determine the independent remediation efficiencies of these media. For effective phytoremediation, the implemented system needs to be capable of remediating pollutants without displaying ecosystem invasive properties. It is for this reason that the phytoremediatory capabilities of individual plant species and a vegetative community as a whole need to be studied.

The purpose of this paper is to demonstrate the design and construction of a laboratory phytoremediation system, capable of establishing the performance of individual plant species and vegetative communities, by investigating agricultural pollutant remediation. In assessing the remediation performance of multiple plants per growth silo, the important role of biodiversity in vegetative assemblages is highlighted. The efficacy of the proposed laboratory method design is tested by comparing the pollutant extraction capabilities of individual, multiple-indigenous and alien wetland plant species commonly used for phytoremediation. 


\section{MATERIALS AND METHODS}

\section{Experimental design}

To evaluate the pollutant extraction capabilities of plant species, the system was required to integrate 5 influent pollutants across multiple growth silos whilst guaranteeing uniform standardized influent irrigation throughout. Growth silos were constructed from polyvinyl chloride (PVC) piping, each containing a threaded slit drainage pipe that protruded from the sealed base of each silo - enabling effluent collection into sampling containers directly below. Silos for individual plants and larger growth silos for multiple species (indigenous and alien) within a singular silo were constructed from PVC, to test the overall contribution of phytoremediation (Fig. 1). The larger silos accommodated 4 plant species within each silo. Voids were cut along the length of the silos for the establishment of plants at different intervals. At each void a plant species was introduced. The quantity per plant species introduced depended on the surface cover associated with that species, for instance, quantity of grasses to be introduced was greater than the quantity of sedges. For each growing compartment (void) a roof-like structure was inserted, ensuring soil stability and preventing collapsed media and pollutants cascading onto and potentially harming the plants.

An equivalent growth medium volume between different silo sizes ensured that the effect of degradation and adsorption by soil was consistent. It is important to acknowledge the remediation effect of soil media within the different silo sizes, thus soil controls associated with the different silo sizes were included.

\section{Soil growth volume calculation}

For the individual plant per silo experiment, the silo dimensions were selected to represent a growth volume (V) capable of supporting rhizosphere processes and plant root growth. Considering that only a portion of the silo is used as growth medium and the rest as a layer of natural filtration, the selected growth medium height for individual species per silo was $30 \mathrm{~cm}$ (Fig. 2).

The selected soil growth volume for all plants was standardized at $2548.46 \mathrm{~cm}^{3}$ (Fig. 2). Growth volume for each plant species was consistent throughout. The soil control volume of the multiple plant species silo combined the soil growth volume of the individual plant species per silo, adapted to represent a combination of four species. As voids were created to allow for efficient plant growth, the growth volumes were adjusted to accommodate the areas lost by the voids.

\section{Drainage layers}

Paired drainage layers comprising of coarse sand and gravel were added below the soil growth, to cover the drainage pipe. These drainage layers prevented sedimentation within the slits of the drainage pipe, preventing clogging of the effluent runoff. The thickness of the drainage layers was comparable with previous urban drainage studies (Bratieres et al., 2008; Read et al., 2008; Milandri et al., 2012)Australia, to test the performance of stormwater biofilters for the removal of sediment, nitrogen and phosphorus. The aim of the study was to provide guidance on the optimal design for reliable treatment performance. A variety of factors were tested,

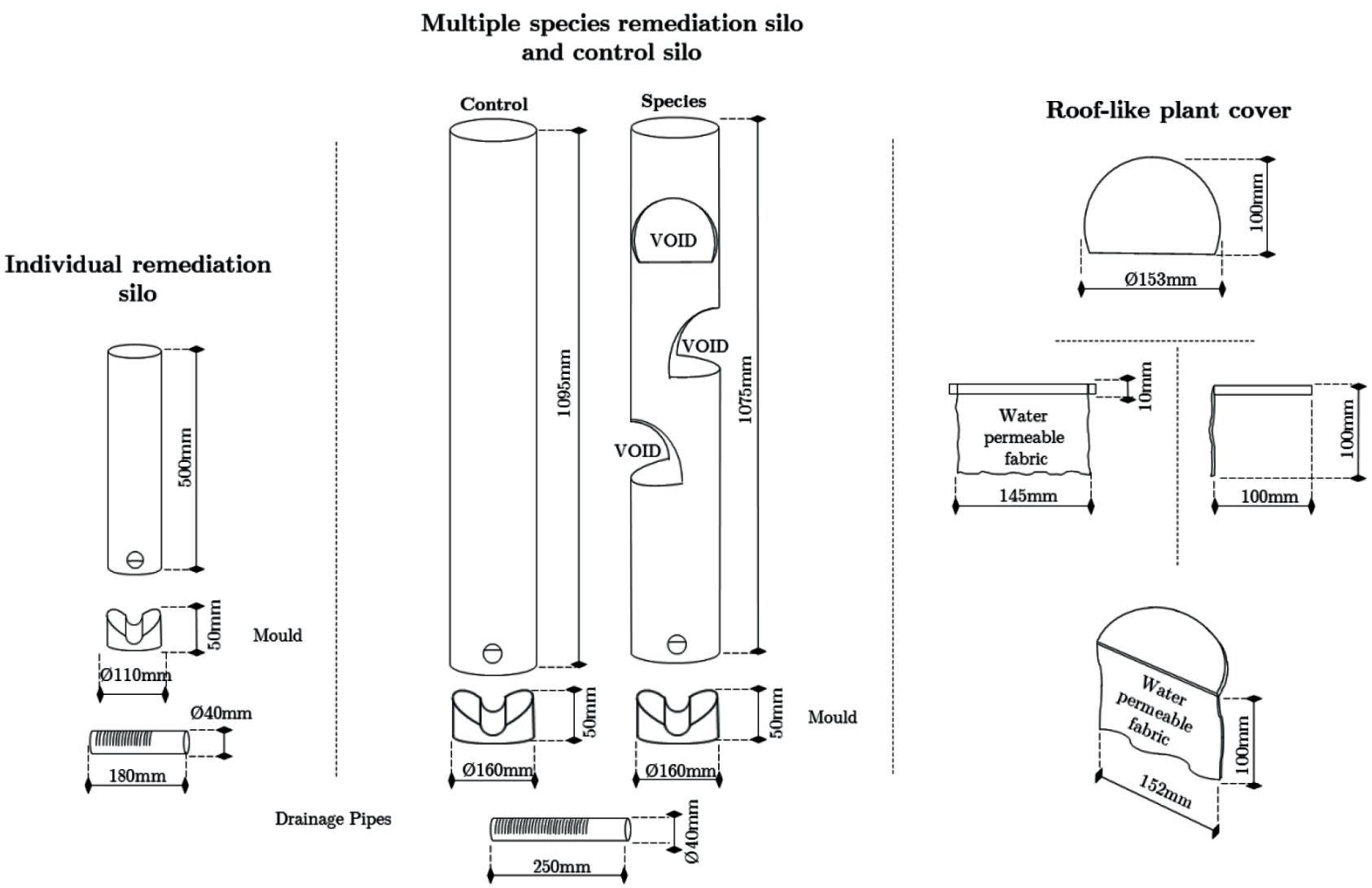

Figure 1. Silo design for individual and multiple species treatments 




Silo volume at void $(\mathrm{cm})$ $V=\pi r^{2} h$

$V=\pi(7.65)^{2}(10)$

$V=1838.539 \mathrm{~cm}^{3}$

Void volume $(\mathrm{cm})$ :

$\frac{2}{3} V=\pi(7.65)^{2}(10)$

$V=1838.539 \mathrm{~cm}^{3} \times \frac{2}{3}$

$V=1225.693 \mathrm{~cm}^{3}$

Volume behind void $(\mathrm{cm})$ :

$V=1838.539 \mathrm{~cm}^{3}-1225.693 \mathrm{~cm}^{3}$

$V=612.846 \mathrm{~cm}^{3}$

Volume required $(\mathrm{cm})$

$x+612.846 \mathrm{~cm}^{3}=2548.460 \mathrm{~cm}^{3}$ $x=1935.614 \mathrm{~cm}^{3}$

Height of volume,

above void $(\mathbf{c m})$ :

$V=\pi r^{2} h$

$1935.614 \mathrm{~cm}^{3}=\pi(7.65)^{2}$

$h=10.529 \mathrm{~cm}$

$h \approx 11 \mathrm{~cm}$

Total growing area per plant: $h \approx 20 \mathrm{~cm}$

$10 \mathrm{~cm}$ height for filtration

정

$12 \mathrm{~cm}$ to ensure no
sediment clogs drainage pipe

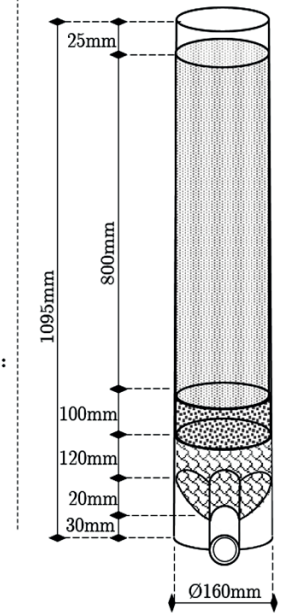

To simulate treatmen of 4 plants: Total height $=4 \times \mathrm{h}$ $4 \times(20 \mathrm{~cm})$ $h=80 \mathrm{~cm}$

$10 \mathrm{~cm}$ height for filtration

$12 \mathrm{~cm}$ to ensure no sediment clogs drainage pipe

Figure 2. Calculation of soil medium required for silo dimensions

using 125 large columns: plant species, filter media, filter depth, filter area and pollutant inflow concentration. The results demonstrate that vegetation selection is critical to performance for nitrogen removal (e.g. Carex appressa and Melaleuca ericifolia performed significantly better than other tested species.

\section{Soil utilized as growth medium}

The soil growth medium was selected to reflect the natural conditions for plant root growth and pollutant adsorption. The use of the soil type which the plants under study are naturally accustomed to alleviates stress during plant extraction and transplantation. For similar studies it is recommended that soil be included which is associated with the plant species under study, as rhizosphere-condition familiarity would minimise the acclimatisation period (Bunt, 2012).

\section{Irrigation}

An automated irrigation system was installed to ensure a consistent irrigation regime with frequency of $72 \mathrm{~h}$. The system contained three submersible pumps, one for each of the three treatments (fertilizer, herbicide and municipal control), submersed within their respective storage containers (Fig. 3). The capacity of each container was $45 \mathrm{~L}$; with each container fitted with an external clear pipe marked to indicate the volume of the solution within. The municipal control container was fitted to a municipal tap to refill the water volume as the submersible pump transported solution to the system. The capacity within the container was controlled by a domestic toilet flow inlet control valve connected to a float ball, to ensure a constant water level. Each submersible pump transferred the water from their respective storage containers using $15 \mathrm{~mm}$ irrigation pipes attached to 35 treatment silos via drippers; each

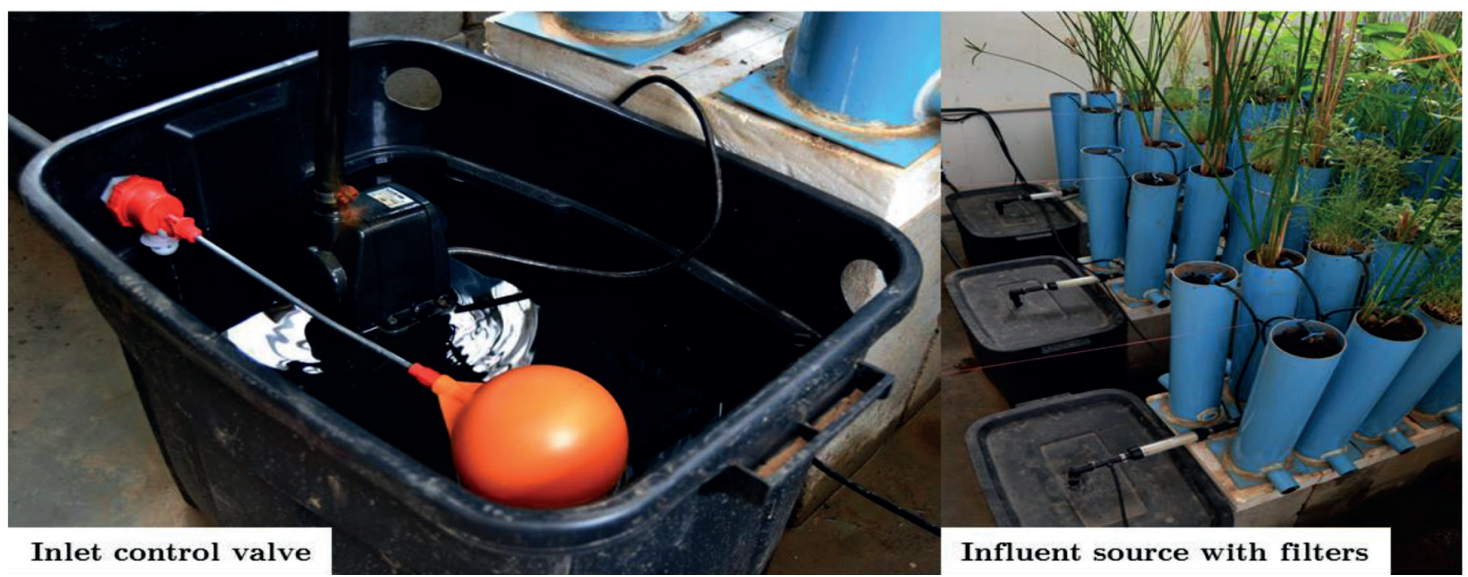

Figure 3. Flow inlet control and submersible pump and a depiction of the irrigation filters 
pipe was fitted with an Emjay filter to remove any material that may impede the flow.

Added storage tanks were constructed for the herbicide and fertilizer containers. Two $70 \mathrm{~L}$ storage tanks were included in the study to increase the mixed herbicide and fertilizer solution capacities. The tanks were placed above the experimental set-up on scaffolding, to allow transport of fluid to the $45 \mathrm{~L}$ containers below, containing the submersible pumps, by gravitational flow. The solution was transported to the submersible pump containers by $15 \mathrm{~mm}$ irrigation lines, controlled with internal valves, with the ability to impede the flow when maintenance on the submersible pump containers was required.

The capacity of the submersible pump containers was controlled by attaching the irrigation inflow, from the storage tanks above to a domestic toilet flow inlet control valve. The valves were connected to float balls. This ensured consistent irrigation of solution volume into the growth silos. Drippers of dissimilar irrigation rates were used for the different silo sizes, $870 \mathrm{~mL} / \mathrm{h}$ and $2070 \mathrm{~mL} / \mathrm{h}$ for the smaller individual plant species silos and the larger multiple plant species silos, respectively.

Treatments consisted of municipal tap water (as the control), a fertilizer solution and a herbicide solution. The solutions were mixed prior to each treatment cycle. Each container housed an additional submersible pump, to prevent stagnation and ensure complete dispersion of nutrients and chemicals. After transplantation, the plants received municipal tap water for 6 months, this period allowed the plants to acclimatize to their new growing conditions. The process was mitigated by establishing similar environmental growing conditions, with the utilization of soil excavated from the selected field study site. The duration of the acclimatization period granted the species sufficient time to develop into stronger, more mature plants and, if any adverse impacts resulting from plant transplantation and translocation were experienced, time to recuperate.

\section{Lighting}

An indoor laboratory phytoremediation system is prone to irregular natural light, limiting uniform plant growth, thus artificial lighting was provided to produce a uniform distribution. The lighting was distributed by fluorescent tubes via Osram Biolux lamps due to their wavelength distribution comparable to sunlight (Osram, 2018). Eight 58W Biolux tubes were mounted throughout the system, placed at specific locations to ensure uniform light distribution. The fluorescent lights were controlled by a mechanical timer, switching the lights on and off according to a programmable schedule. The timer was programmed to display light between 05:30 and 20:00, to reflect natural growing conditions.

\section{Plants for phytoremediation}

Plant species vary with regard to their pollutant removal abilities, with the most effective plant species characterised by long roots, deep root depth, and heavy root mass (Read et al., 2010). The introduction of certain plant species for phyto-extraction may, however, pose a set of alien invasive problems, necessitating investigation into the removal efficiencies of plant species indigenous to contaminated areas (Schachtschneider et al., 2010; Leguizamo et al., 2017). For this reason, indigenous South African plant species were included for plant-based biofilter investigation. Various phytotechnologies utilize different plant properties and typically implement different plant species for each scenario. Properties that have been accepted as advantageous to phytoremediation are: fast growing, high biomass, competitive and high tolerance to pollution (Pilon-Smits, 2005).

The pollutant removal efficiency of indigenous plant species and invasive alien plant (IAP) and Palmiet species (commonly used in phytoremediation) were investigated and compared. A sample of indigenous plants displaying non-invasive properties, and being potentially capable of remediating pollutants with either matching or superior efficacy to the IAP, and Palmiet species are tested. The implementation of these species as phyto-extractors, rather than their potentially invasive counterparts, benefit biodiversity conservation initiatives.

\section{Plant collection and transplantation}

The plant species were all either removed from areas where they naturally occur, from drainage canals and catchments, or sourced from nurseries in the Western Cape, South Africa. During the transplantation process, special attention was given to remove all visible foreign organic matter from the soil. This limited the contribution of any external factors during the phytoremediation process, ensuring equal conditions throughout the growth silos. Immediately following transplantation, the specimens received municipal tap water irrigation for 6 months, allowing time to mature and adjust to growing conditions. Thereafter, the plants received standardized contaminated fertilizer and herbicide water treatments. From Fig. 4, the individual plant species experiment and alien vs. indigenous community comparison experiment layout is depicted in the constructed laboratory system. Species locality was selected to minimise the effect of a dominant neighbour, creating a canopy and hindering light distribution, further inhibiting uniform growth.

\section{Pollutants}

The dosing concentrations of nitrogen $(\mathrm{N})$ and phosphorus $(\mathrm{P})$, viz. $46.376 \mathrm{mg} / \mathrm{L}$ and $17.391 \mathrm{mg} / \mathrm{L}$, were selected as a result of recommendations from the Department of Agriculture, Forestry and Fisheries (DAFF) for site-specific agricultural practices affecting the watercourses under study (DAFF, 1996). Three analytical grade compounds were used to create a fertilizer mixture similar to the recommended products. In commercial fertilizers ammonia $\left(\mathrm{NH}_{4}\right)$ and nitrate $\left(\mathrm{NO}_{3}^{-}\right)$is generally the

Table 1: Synthetic fertilizer concentrations

\begin{tabular}{|c|c|c|c|c|c|}
\hline \multicolumn{3}{|c|}{ DAFF recommendation } & \multicolumn{3}{|c|}{ Representative analytical substances } \\
\hline Nutrient & Product & Conc. (mg/L) & Representative substance & Formula & $\begin{array}{c}\text { Representative } \\
\text { substance conc. (mg/L) }\end{array}$ \\
\hline \multirow[t]{2}{*}{$\mathrm{N}$} & $\mathrm{NH}_{4}^{+}-\mathrm{N}$ & 37.096 & Ammonium chloride & $\mathrm{NH}_{4} \mathrm{Cl}$ & 141.659 \\
\hline & $\mathrm{NO}_{3}{ }^{-}-\mathrm{N}$ & 9.274 & Potassium nitrate & $\mathrm{KNO}_{3}$ & 66.939 \\
\hline$P$ & $\mathrm{PO}_{4}^{3--} \mathrm{P}$ & 17.39 & Di-Potassium-H-phosphate & $\mathrm{K}_{2} \mathrm{HPO}_{4}$ & 97.788 \\
\hline
\end{tabular}




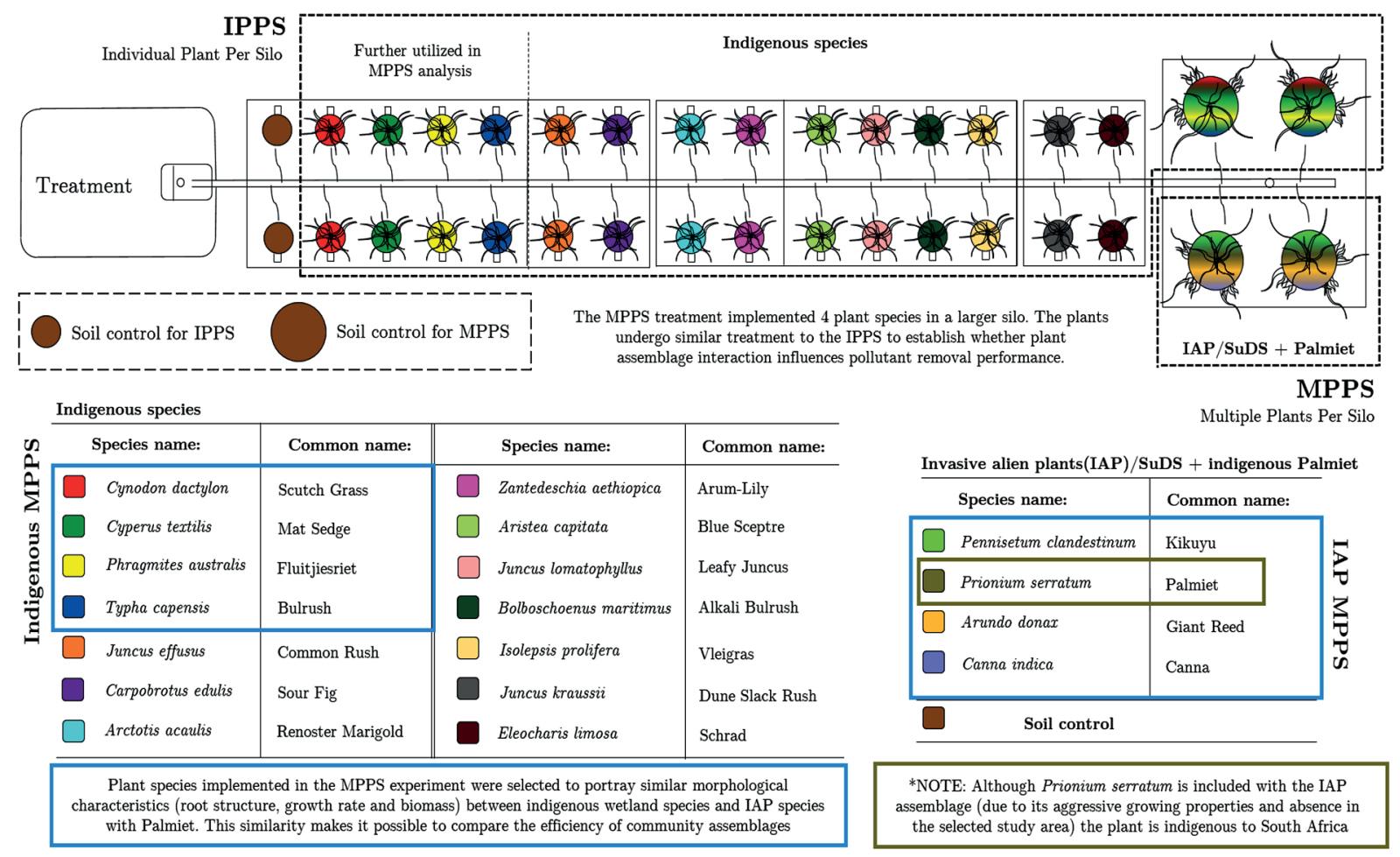

Figure 4. Species distribution within the laboratory phytoremediation system

source of $\mathrm{N}$ with phosphate $\left(\mathrm{PO}_{4}^{3-}\right)$ the source of $\mathrm{P} . \mathrm{N}$ and $\mathrm{P}$ are represented by $\mathrm{NH}_{4} \mathrm{Cl}+\mathrm{KNO}_{3}$ and $\mathrm{K}_{2} \mathrm{HPO}_{4}$ respectively. The concentration of the analytical grade compound is calculated from the initial $46.376 \mathrm{mg} / \mathrm{L} \mathrm{N}$ and $17.391 \mathrm{mg} / \mathrm{L} \mathrm{P}$.

A glyphosate-based herbicide was selected to represent the agricultural herbicide pollutant on a basis of relevance, as a result of its popularity in the agricultural sector. The agricultural practices under study apply Springbok 360 SL, a product of Arysta LifeScience, prior to planting crops and after a rainfall event. Two glyphosate concentrations were selected for this study, viz. $0.7 \mathrm{mg} / \mathrm{L}$ glyphosate and $225 \mathrm{mg} / \mathrm{L}$ glyphosate; representing a non-toxic contamination to aquatic ecosystems and a worst-case scenario acute contamination, respectively.

\section{Contamination treatment}

After the initial 6-month water irrigation, the pollutant treatments commenced. The irrigation regime, every 3 days, was based on the saturation and permeability of the growth silos. A dosage of $0.653 \mathrm{~L} / 3$-day and $1.553 \mathrm{~L} / 3$-day, for the individual plant species per growth silos and multiple plant species per growth silos, respectively, was regarded as the optimum volume and rate for irrigation. Every 10 days the influent solutions were drained and replaced with a fresh mixture of pollutants, thus hindering the effect of pollutant degradation in the storage tanks.

\section{Sampling process}

Samples were collected on 5 occasions during the study. The first round of sampling was for the purpose of examining the baseline nutrient concentrations. This determined the nutrient concentrations within the growth silos prior to treatment. The baseline determination allowed for precise comparison between influent and effluent water. The percentage removal by all specimens was compared as influent concentrations were premixed to known standardized concentrations and baseline concentrations were known. Sampling intervals ensured sufficient time for previous dosage solutions to percolate through the column, ensuring influent removal analyses were not duplicated over the duration of the experiment. Sampling time correlated with the proposed irrigation schedule for agricultural activities applicable where the plants are distributed (DAFF, 2016).

Treated effluent water was collected with collection containers directly below the drainage pipes of each growth silo. Two plants per species received treatment, establishing experimental duplication and reducing outlier influence. The effluent solutions were collected in $90 \mathrm{~mL}$ specimen containers, with twin plant species' effluent solutions mixed post effluent collection.

\section{Analysis}

In order to evaluate the efficacy of the experiment's pollutant removal, various water quality parameters were measured throughout the experiment. These include $\mathrm{pH}$, dissolved oxygen (DO), electrical conductivity (EC), nitrogen in ammonia $\left(\mathrm{NH}_{3}-\mathrm{N}\right)$, nitrogen in nitrate $\left(\mathrm{NO}_{3}{ }^{-} \mathrm{N}\right)$, phosphorus in orthophosphate/soluble reactive phosphorus $\left(\mathrm{PO}_{4}{ }^{3-}-\mathrm{P} / \mathrm{SRP}\right)$ and glyphosate $\left(\mathrm{C}_{3} \mathrm{H}_{8} \mathrm{NO}_{5} \mathrm{P}\right)$.

The $\mathrm{pH}, \mathrm{DO}$ and EC were measured using the HQ440d Benchtop Multi-Parameter Meter manufactured by Hach. The $\mathrm{NH}_{3}-\mathrm{N}, \mathrm{NO}_{3}{ }^{-}-\mathrm{N}$ and $\mathrm{PO}_{4}{ }^{3-}-\mathrm{P}$ concentrations were measured colorimetrically using the DR3900 Benchtop Spectrophotometer and their associated TNTplus test kits. For glyphosate analysis, the acuity ultra-performance liquid chromatography (UPLC) was coupled to a Xevo Triple Quadrupole Tandem Mass Spectrometer (MS/MS) and used for high-resolution UPLC-MS/ MS analysis (Waters, 2018). Glyphosate was further separated 
by multiple reactions monitoring (MRM) using electrospray ionisation in a positive mode.

\section{RESULTS AND DISCUSSION}

The experimental design allows for the comparison of chemical removal in vegetated silos and that of the soil medium control. This allows for the determination of the relative chemical absorption by both the plant and soil components. The system further indicated that there is potential to rather integrate the indigenous plant species as an alternative to their alien counterparts currently used in local and international constructed wetlands, SuDS and biofiltration systems.

In evaluating removal efficiencies (the difference between the influent and effluent concentrations), baseline concentration values need to be known. The baseline values indicate the initial nutrient content within the growth silos prior to the addition of pollutants. Without this information, one cannot deduce the removal efficiencies of the system. The initial baseline concentration of every growth silo was measured before contaminants were added to the system. Baseline concentrations were deducted from the effluent concentrations to allow for the calculation of percentage removal for each sampling round. The following equation was used:

$$
\frac{\text { Influent conc. }-(\text { Effluent conc. }- \text { Baseline conc. })}{\text { Influent conc. }} \times \frac{100}{1}
$$

where:

Influent conc. $=$ Influent concentration $(\mathrm{mg} / \mathrm{L})$

Effluent conc. = Effluent concentration $(\mathrm{mg} / \mathrm{L})$

Baseline conc. $=$ Baseline concentration $(\mathrm{mg} / \mathrm{L})$

The Kruskal-Wallis $H$-test, non-parametric ANOVA, was used for the evaluation of Renosterveld phytoremediation vs. unvegetated soil; thereafter a Student's $t$-test was used for the evaluation of multiple indigenous wetland plant species vs. multiple IAP species and Palmiet. Statistical analyses were executed in Python by means of the data analytical library.

\section{Phytoremediation versus unvegetated soil}

Confirming the remediation capabilities of vegetation, the concentration of pollutants removed by individual plant species was compared to the pollutants removed by the unvegetated soil silos. The percentage pollutant removal is depicted on the



Figure 5. Mean nutrient percentage removal vertical axis as a function of time, indicating days of sampling. The initial baseline nutrient and herbicide concentrations were taken into consideration to allow for comparison between influent and effluent. Figure 5 compares the average percentage removal of all nutrients $\left(\mathrm{NH}_{3}-\mathrm{N}, \mathrm{NO}_{3}{ }^{-}-\mathrm{N}\right.$ and $\left.\mathrm{PO}_{4}{ }^{3-}-\mathrm{P} / \mathrm{SRP}\right)$ for vegetation and the unvegetated soil control for the duration of the experiment.

The plant species all reduced the effluent concentration of the nutrients. The percentage removal averaged $85.75 \%, 86.62 \%$ and $87.78 \%$ for $\mathrm{NH}_{3}-\mathrm{N}, \mathrm{NO}_{3}{ }^{-}-\mathrm{N}$ and $\mathrm{PO}_{4}{ }^{3-}-\mathrm{P}(\mathrm{SRP})$ respectively. The average percentage nutrient removal in Fig. 5 indicates that the vegetation, on average, was more effective in the removal of nutrient pollutants than was soil, attributed to the phytoremediatory capabilites of plants. There was no obvious difference between $\mathrm{NH}_{3}, \mathrm{NO}_{3}{ }^{-}$and $\mathrm{PO}_{4}{ }^{3-}$ remediation within vegetation, whereas considerable percentage nutrient removal variation existed between vegetated and unvegetated media.

Similar to the fertilizer nutrients, the vegetation removed a greater percentage of both $0.7 \mathrm{mg} / \mathrm{L}$ glyphosate and 225 $\mathrm{mg} / \mathrm{L}$ glyphosate, compared to soil only. Although, from Fig. 6, percentage removal of the unvegetated soil was comparatively high, it is evident that vegetation more effectively remediated pollutants at both glyphosate concentrations. The percentage removal of the soil control dropped with time, indicating herbicide accumulation in the absence of vegetation, resulting in increased leaching and transportation of glyphosate, whereas vegetative performance remained constant. Environmentally, glyphosate leachate results in increased agricultural pollution of adjacent freshwater aquatic systems.

\section{Indigenous versus alien plants plus Palmiet}

In comparing the removal efficiencies of indigenous species and alien species currently implemented locally and internationally, the feasibility of replacing alien plants with local species was tested. Plants of similar physiology were selected for community comparison. The indigenous wetland species selected for this test included: Phragmites australis, Cyperus textilis, Typha capensis and Cynodon dactylon, which can be found in Renosterveld vegetation regions among others. The alien species were: Canna indica, Arundo donax and Pennisetum clandestinum. Prionium serratum, a South African indigenous plant species, is included with the alien assemblage due to its aggressive growth properties and absence in the agricultural area of interest in this study.

Figure 7 represents the mean percentage pollutants removed between the indigenous samples, the alien samples with Palmiet and the unvegetated soil control. It was inferred

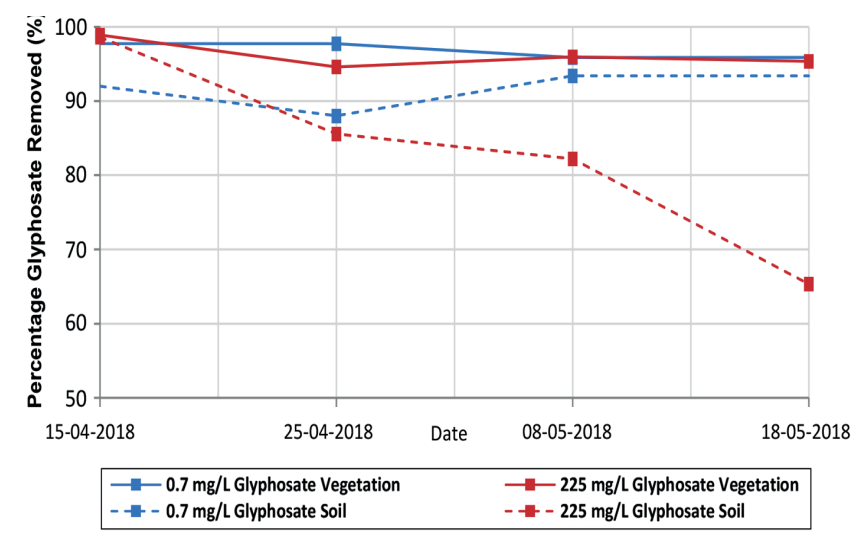

Figure 6. Mean herbicide percentage removal 


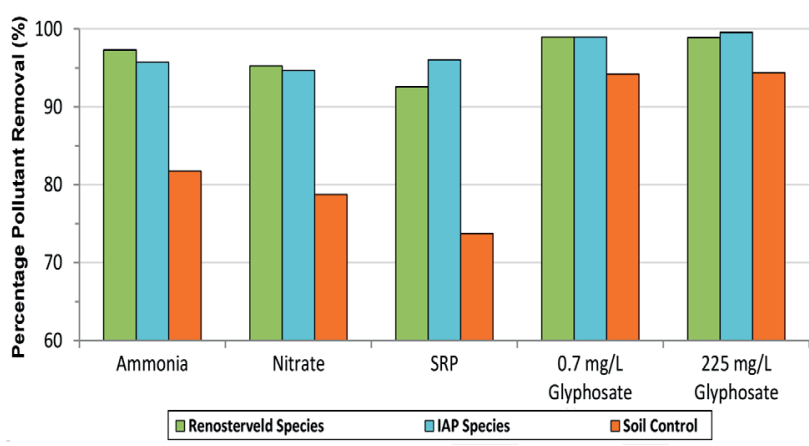

Figure 7. Percentage pollutant removal of the indigenous assemblage, IAP + Palmiet assemblage and unvegetated soil control

that there was no evidence that suggested one sample group to be more effective in removing pollutants than the other. It was however evident that both the Renosterveld and alien assemblages were more effective in the removal of pollutants than the unvegetated soil control. These comparative removal abilities of the two plant groups show the indigenous plant group to be as effective as internationally used species. This therefore supports the recommendation of rather implementing indigenous plants than their more invasive counterparts for remediation in sensitive contaminated sites.

\section{CONCLUSIONS}

The designed system allowed for the evaluation of the phytoremediatory capabilities of selected plant species. This design and the use of the multiple plant silo allows for the comparison of indigenous species efficacy with that of alien plants commonly used for phytoremediation. The findings produced by the experimental system are comparable with literature from previous local and international studies, indicating the system accurately measures phytoremediatory capabilities of plant species. The system has been specifically designed to evaluate individual plant species of varying physiology and may thus be used to analyse species occupying different habitat types, i.e., wetland or dryland. Plant species can be successfully evaluated in terms of bioremediation capabilities, with the opportunity to incorporate different soil types (growth media) and pollutants. However, silo width plays a significant role, where pollutants are intercepted by a dense root system more effectively. The contaminants bind to the root structure and cell walls and hemicellulose within the cell wall and bind hydrophobic organic chemicals. The system is not limited to seasonal variability and conditions, granting the researcher the freedom to analyse pollutant remediation throughout the year. Further, proven effective plant species need to be investigated in a field setting, and with a cost analysis included.

\section{ACKNOWLEDGEMENTS}

This research was funded by The Rufford Foundation (UK), with project identity: [23296-1].

\section{REFERENCES}

BARCELO D (1997) Trace Determination of Pesticides and their Degradation Products in Water. Elsevier, Amsterdam.

BELTRANO J, RUSCITTI M, ARANGO C and RONCO M (2013) Changes in the accumulation of shikimic acid in mycorrhized Capsicum annuum L. grown with application of glyphosate and phosphorus. Theoretical and Experimental Plant Physiol. 25 (2) 125-136. https://doi.org/10.1590/S2197-00252013000200005

BRATIERES K, FLETCHER TD, DELETIC A and ZINGER Y (2008) Nutrient and sediment removal by stormwater biofilters: a largescale design optimisation study. Water Res. 42 (14) 3930-3940. https://doi.org/10.1016/j.watres.2008.06.009

BUNT AC (2012) Media and Mixes for Container-Grown Plants: A Manual on the Preparation and use of Growing Media for Pot Plants. Springer, London.

CAMPBELL CS (1999) Constructed Wetlands in the Sustainable Landscape. John Wiley and Sons, New York.

RSA (Republic of South Africa) (1996) Fertilizers, Farm Feeds, Agricultural Remedies and Stock Remedies Act. Act No. 36 of 1947. Government Printer, Pretoria.

DAFF (Department of Agriculture, Forestry and Fisheries, South Africa) (2016) Production guideline for canola. DAFF, Pretoria.

DONOSO G, CANCINO J and MAGRI A (1999) Effects of agricultural activities on water pollution with nitrates and pesticides in the Central Valley of Chile. Water Sci. Technol. 39 (3) 49-60. https:// doi.org/10.2166/wst.1999.0134

HASHEMI F, OLESEN JE, DALGAARD T and BØRGENSEN CD (2016) Review of scenario analyses to reduce agricultural nitrogen and phosphorus loading to the aquatic environment. Sci. Total Environ. 573 608-626. https://doi.org/10.1016/j. scitotenv.2016.08.141

KENNEN K and KIRKWOOD N (2015) Phyto: Principles And Resources For Site Remediation And Landscape Design. Routledge, London. https://doi.org/10.4324/9781315746661

LAM QD, SCHMALZ B and FOHRER N (2010) Modelling point and diffuse source pollution of nitrate in a rural lowland catchment using the SWAT model. Agric. Water Manage. 97 (2) 317-325. https://doi.org/10.1016/j.agwat.2009.10.004

LEGUIZAMO MAO, GÓMEZ WDF and SARMIENTO MCG (2017) Native herbaceous plant species with potential use in phytoremediation of heavy metals, spotlight on wetlands: a review. Chemosphere 168 1230-1247. https://doi.org/10.1016/j. chemosphere.2016.10.075

MILANDRI SG, WINTER KJ, CHIMPANGO SBM, ARMITAGE NP, MBUI DN, JACKSON GE and LIEBAU V (2012) The performance of plant species in removing nutrients from stormwater in biofiltration systems in Cape Town. Water SA 38 (5) 275-662.

NORSE D (2005) Non-point pollution from crop production: Global, regional and national issues. Pedosphere 15 (4) 499-508.

NORSE D, LI J, JIN L and ZHANG Z (2001) Environmental Costs of Rice Production in China: Lessons from Hunan and Hubei. Aileen International Press, Bethesda.

OSRAM (2018) Biolux T8 Product data sheet. URL: http:// www.osram.com/osram_com/products/lamps/ fluorescentlamps/\%0Afluorescent- lamps-t8/fluorescent-lamps-t8special-versions/biolux-t8/index.jsp (Accessed 17 July 2017).

PILON-SMITS E (2005) Phytoremediation. Annu. Rev. Plant Biol. 56 15-39. https://doi.org/10.1146/annurev.arplant.56.032604.144214

READ J, FLETCHER TD, WEVILL T and DELETIC A (2010) Plant traits that enhance pollutant removal from stormwater in biofiltration systems. Int. J. Phytoremed. 12 (1) 34-53. https://doi. org/10.1080/15226510902767114

READ J, WEVILL T, FLETCHER TD and DELETIC A (2008) Variation among plant species in pollutant removal from stormwater in biofiltration systems. Water Res. 42 (4-5) 893-902. https://doi.org/10.1016/j.watres.2007.08.036

SCHACHTSCHNEIDER K, MUASYA M and SOMERSET V (2010) Are indigenous sedges useful for phytoremediation and wetland rehabilitation? Report no CSIR NE04-PO. CSIR, Pretoria.

SCHOUMANS OF, CHARDON WJ, BECHMANN ME, GASCUELODOUX C, HOFMAN G, KRONVANG B, RUBAEK GH, ULÉN B and DORIOZ JM (2014) Mitigation options to reduce phosphorus losses from the agricultural sector and improve surface water quality: a review. Sci. Total Environ. 468 1255-1266. https://doi. org/10.1016/j.scitotenv.2013.08.061

SMITH LED and SICILIANO G (2015) A comprehensive review of constraints to improved management of fertilizers in China and mitigation of diffuse water pollution from agriculture. 
Agric. Ecosyst. Environ. 209 15-25. https://doi.org/10.1016/j. agee.2015.02.016

TERRY N and BANUELOS GS (1999) Phytoremediation of Contaminated Soil and Water. Ringgold, Portland. https://doi. org/10.1201/9781439822654

TESFAMARIAM T, BOTT S, CAKMAK I, RÖMHELD V and NEUMANN G (2009) Glyphosate in the rhizosphere - role of waiting times and different glyphosate binding forms in soils for phytotoxicity to non-target plants. Eur. J. Agron. 31 (3) 126-132. https://doi.org/10.1016/j.eja.2009.03.007

WATERS (2018) Xevo TQ-XS Triple Quadrupole Mass Spectrometry. URL: http://www.waters.com/waters/en_ZA/ Xevo-TQ-XS-Triple-Quadrupole-Mass-Spectrometry/nav. htm?cid=134889751\&locale=en_ZA (Accessed 15 May 2018). 